\title{
Can Finance and Credit Enable Economic Growth and Democracy?
}

\author{
Bassem Snaije
}

Abstract

Can economic growth and democracy be fuelled by finance and credit? This chapter examines mechanisms that have positive effects on democratic transition in the Middle East and North Africa (MENA) region, such as credit growth and the development of capital markets-based credit, based on a bond market and a Sukuk market, its sharia-compliant equivalent. The contribution analyses the general role of credit as a network of legally binding contracts of trust between economic actors, including the state, in any given country. By comparing the role and size of credit in the Organisation for Economic Co-operation and Development (OECD) countries and the MENA region, the author argues that, in general, the growth of credit's role in MENA countries and, in particular, the development of debt capital markets in the region, strengthen public participation in the economic activity of the region. The spread of contractual obligations requires more transparent and accessible accounting and financial reporting, and a wider network of legally binding obligations. These powerful mechanisms therefore facilitate democratic transitions in MENA countries, even in autocratic regimes.

1

\section{Introduction}

A democratic system provides 'trust between the largest number of people who do not know each other' (Leca, 2014). It is in this context that finance and credit play the important, or even central, role of providing monetary means towards industrial or commercial opportunities fuelling economic growth. In this chapter, we will examine how the financial sector, and particularly credit activity in the Arab world, can contribute to transitions to more democratic processes through fostering economic growth, and trust based on rules and institutions rather than on previous acquaintance. We will compare the place and role of credit in the Organisation for Economic Co-operation and Development (OECD) countries and in the Middle East and North Africa (MENA) 
and discuss how it could promote or impede transitions to more democratic processes and economic growth in the Arab world.

The capital markets of the major OECD nations are fuelled by credit in its various forms. The banking industry and capital markets have created an economic environment, mainly through the use of debt, that is an essential component of economic activity and a determinant of the monetary policies of central banks. Credit inventories mirror the nature of economic activity, and new credit that becomes available reflects developing trends in economic activities. The financial sector, and more specifically credit (rather than equity investment), can therefore be considered the cement that binds together all the components of a given economy: producers, consumers, regulators and government agencies alike.

Financial contracts, and specifically credit availability and development, represent the agreements of trust between the parties involved in producing and consuming finance and credit. This network of agreements of trust enables the highest number of economic agents to participate in economic activity and contribute to the growth of the gross domestic product (GDP). The wider the network of trust is, the more inclusive the economy and the higher the potential for the development of a country's GDP.

Using these fundamental equations, the central role that credit plays is clear. But the role of credit is only possible if the inventory built on agreements of trust is within a given framework of rules. All parties-whether providers of credit, or agents accessing it to fuel their activity—must agree to these rules in a general consensus. The credibility and effectiveness of agreements of trust are thus a function of this framework, which is in fact a democratic framework in as much as it is not controlled from the top down, but responds to multiple, independent, decentralized decision-making.

The governance of advanced credit systems is composed principally of the following elements:

- An independent judicial system-Independent courts with fully developed commercial and bankruptcy laws.

- Licenses and Permits - In order to produce, distribute and manage credit, banks and financial institutions should operate within a set of regulations that impose conditions for the volume and price of credit, and that 
determine which corporations, entities or individuals can access it. Banks and financial institutions must be licensed within the context of governance to which all parties subscribe.

- Regulatory bodies - Independent or neutral entities (central banks, capital markets authorities, and stock market boards) should oversee the functioning of the system.

- Information-Composed from data representing the components of credit (prices, volumes and conditions), and from the elements of risk and the price of non-performance for each transaction. Information should include documents provided by the credit distributors describing the products and their risks to potential clients, as well as the appropriate disclaimers and reports that facilitate the understanding and management of the evolution of these products over time. Information is also a function of the governance context in which credit operates, and this context should make all economic data and accounting standards available to active participants. A democratic framework provides for central, independent information institutes (national statistics institutes) and a general set of accounting and fiscal regulations, allowing all parties contracting credit transactions to have access to the same information.

The closer a country comes to this framework, the better the conditions for credit availability and growth are. It is not by accident that countries that have developed the most advanced credit systems and frameworks have democratic institutions. It is difficult to expect that appropriate conditions for a well-developed credit system may obtain under authoritarian regimes, which inevitably rely on limitations to the rule of law, to data transparency, to independent institutions, and to freedom of enterprise.

\section{The Financial Structures of OECD and MENA Economies Show Significant Differences}

The most developed credit systems are found in OECD member countries, the majority of member states having economies that operate with most of the desirable conditions we have described, delivering the most creditable set of 'trust contracts' to the largest possible number of participants in their economies. In OECD countries, banks' share of the total funding of the economies of member states is on average in a range of 33 to 35 per cent (OECD, 2014); capital markets' share is between 65 and 67 per cent. Within capital markets, stock markets and equities contribute between 25 and 30 per cent, and bonds between 40 and 42 
per cent of the total. This shows that credit's share of total sources of finance in OECD countries as a whole amounts to 75 per cent on average.

This places credit at the centre of the OECD's economic activities, an assessment consistent with the theoretical position that credit should have in the context of developed democratic frameworks. Two primary characteristics emerge when looking at the structure of OECD country balance sheets in the banking sector:

1. Banks fully play the role of 'transformation' or gap management by having longer-term assets and relatively shorter-term liabilities. For example, within the EU, loan-to-deposit ratios show the transformation of bank deposits, which account for 50 to 60 per cent of banks' very short-term liabilities, into assets that are longer than two years (ЕCB, 2014).

2. Bank balance sheets show a relatively high level of leverage towards capital availability. The median equity-to-total-assets ratios in the eurozone banking sector are between 6 and 8 per cent. If one uses a stricter definition of capital, such as equity over total bank liabilities, these ratios are even lower.

This indicates high leverage in the sector, which confirms the level of trust in the governance framework surrounding the inventory of credit delivered through this channel, and a high level of confidence in the mechanisms in place to guarantee the protection of rights and the execution of clauses in the multitude of contracts struck between all parties related to this credit inventory. This can be considered a confirmation of the credibility of the governance framework provided by the democratic context in OECD countries.

The structures of MENA economies paint a very different picture. In early 2000, the financing structure was composed of banks, with a total share of 80 to 85 per cent, with equity markets representing 12 to 15 per cent on average and bond markets a mere 2 to 3 per cent (IMF, 2004). These numbers changed with the rise of stock markets during the years preceding the 2008 crisis, with the share of stock markets reaching 45 per cent or more (in 2007), decreasing again to $26-27$ per cent in 2008 , and then stabilising around 35 per cent in recent years. The share of bonds and debt securities has increased significantly in the last decade, doubling in size and number of issues. While this is an important change, the starting point was very low. Banks' share, while decreasing over the period, remains very high at around $67-68$ per cent (Kern, 2012).

The primary difference in MENA's financing structure is the dominant role bank credit plays in economic activities. Moreover, state banks account for 
38-40 per cent of total available bank credit (Farazi et al., 2011). However, state banks' share has decreased in the last ten years: the above ratio is an average covering all MENA economies, and the figure varies significantly from one country to another. On average, state ownership of banks in the member countries of the Gulf Cooperation Council (GCC) has significantly decreased during the last decade, but in comparison to the OECD average it remains higher by a factor of 2 to 2.5 times. In the other MENA countries this ratio has decreased far less, and in some cases has remained very high, with state-owned banks accounting for more than 70 per cent of total bank credit.

The balance sheets of banks from the MENA region show that a majority of their loans have maturities of one year or less, which indicates a lack of transformation in these banks' financing activities.

Capital adequacy ratios (CARs) in the GCC banking sector-where the percentage of direct state ownership is the lowest-were in the range of 18 to 20 per cent in 2003. These ratios were impacted by the 2008 financial crisis, but in a limited way, leaving them closer to the level of 15 to 17 per cent. Some countries were affected more than others; in particular the UAE's banking system was hit the hardest in relative terms, with the CAR decreasing from 18 to 12 per cent. While this is a significant decrease (a 35 to 40 per cent deterioration of the ratio is a very significant impact by any standards), a 12 per cent ratio remains very high compared to ratios observed in OECD countries (Khamis, 2010).

The total inventory of credit to the private sector in MENA countries represents a mere 50 per cent of GDP, while in OECD member states as a whole this ratio reaches $15^{\circ}$ per cent of GDP. This is an indication of the significant difference in the role of credit in MENA. Although banks seem to have an important share in the economies of the region, they do not perform with the same ratios as those observed in OECD countries, delivering on average one year maturity loans-a figure that is 2.5 times lower than in OECD countries. This is low leverage given the high capital adequacy ratios they maintain. Moreover, the relatively high number of state-owned banks should discount the banking sector's share in MENA credit activity.

Such low performance leads to exclusion. A study carried out by the World Bank Financial Access Group in 2010 (CGAP, 2010) shows that small and medium-sized companies in OECD countries receive close to 27 per cent of total loans, while the figure is only 7.6 per cent for MENA countries. The study also shows that in OECD countries the number of bank accounts per 1,00o adults is 2,300, of which 750 are loan accounts - an indicator of access to the credit pool available in the economy. This compares with only $75^{\circ}$ accounts per 1,00o adults in MENA, of which only around 100 are loan accounts. Another study, carried out by the IMF in 2007, shows-if any additional proof were needed-that 
in the Us approximately go per cent of the population has access to financial services; in Europe this figure is about 75 per cent; and in MENA countries only about 30 per cent.

All these elements show that banks in MENA are highly capitalised, meaning that their potential to deliver credit is much higher than their actual contribution. Additionally, the credit they provide is very short term. This is partly a result of limited access to risk assessment tools, the absence or poor reliability of data that would allow a robust credit scoring system, and the difficulty of accessing a set of enforceable guarantees that would allow them to project credit risk visibility towards longer average maturities for their loans.

\section{Finance and Democracy in MENA}

Given the financial structure of the economies in the MENA region, the role credit plays is consistent with a relatively poor democratic environment delivering a weak governance framework due to the deficit in the enabling environment. MENA countries' economies are therefore fuelled by a top-down conversation, in which banks are dominant and debt securities providing credit through capital markets offer a limited contribution and alternative to bank financing. Moreover, family groups and individuals close to ruling families or to members of the states' regimes dominate the ownership structure of private sector banks with a significant size and market share. This promotes credit access only to a reduced perimeter of participants who enjoy personal relationships with members of the ownership structure itself. Name lending, rather than credit scoring and financial solvency ratios, becomes the basis for credit access.

These examples of exclusion show how the position of credit in MENA economies creates links dependent on agreements of trust between people who already know each other, and are linked together in a manner that is not necessarily based on economic ventures. This can lower the publicly disclosed accountability requirements that would impose a governance framework more consistent with a democratic environment.

With credit's low share of MENA economies' financing, and the banking sector being the main source for its allocation, access to financial and economic opportunity remains a 'closed' process. The ownership of banks validates the consensus of power in place and keeps gatekeeping privileges in the hands of those close to the ruling structures in MENA. This slows down the entry of new participants into the economy unless those individuals possess substantial amounts of capital and, thus, do not need to access credit. 
In OECD countries as a whole, credit is the central element of economic activity as indicated by the size of the inventory over total GDP. The share of the banking sector is significant, but the share of credit generated in the capital markets is even larger.

Capital markets-based financing appears to thrive and seems consistent with significant and credible democratic processes. Debt securities sold to investors demand a different type of conversation, in which the terms of the contractual agreements, commitments and obligations of the parties involved are more balanced-investors placing their trust in a transaction no longer need to do so based purely on personal connections. Rather, a given transaction would be a business proposal, a project or a cash flow, presented to investors in a conversation in which there is no certainty of the outcome in advance and the price is not fixed by a dominant party, such as a bank, in a market where alternative means of accessing financing are scarce.

The process of financing through a debt security is, in a sense, a voting process (although one in which voting powers are unequally distributed). It implies disclosure, transparency of information at inception, the obligation for information to be available throughout the life of the transaction and a set of clauses designed to manage problems, delays, and potential default. Credible enforcement agencies are necessary to convince both investors and borrowers seeking an alternative method of financing their projects. This is very clear with respect to the market for government bonds, where a government's misbehaviour is punished by an increase in the cost of borrowing and a loss of legitimacy, even if that government does not face the test of an imminent election. It is also one reason why many governments prefer to borrow internationally rather than expose themselves to the judgment of domestic investors and credit markets.

In general, bond market growth assumes a level of financial and accounting disclosure, which is necessary for the credibility of the interest payments that the transaction promises to deliver to the subscribers. This exchange of promises backed by sufficient financial and legal documentation from the issuers, and the delivery of accounting and financial tools to the investors in order to convince them first, and encourage them to increase their investments in existing or new issues, is effectively based on many elements of democratic processes and governance frameworks. Agreements of trust between people with no previous connection are able to expand, mirrored by the bond transactions representing this trust. The price of these bonds at inception, and the evolution of that price through independent actions of selling or buying units of the bond issue indicate the reaction of people with no previous connection to 
the issuers and assess the level of trust that these people have. This is a typical example of capital market voting behaviour, implying independent decisionmaking based on required information, disclosure, transparent price fixing and access to the mechanisms of investing or divesting, buying or selling in an anonymous process.

The growth of credit through the issuance of bonds is therefore an important development; it encourages behaviour and expectations within the economic sphere, which can support the transition towards more democratic behaviour in the political realm. It allows the number of participants in economic activity to increase. The trust and links are no longer between previously connected parties, allowing the number of conversations and growth impulses to increase. Increasingly available and accessible credit fosters economic expansion.

In MENA, the amount of credit available through debt securities is limited compared to the dominant share of the banking sector. However, as described above, the rate of growth in different segments of the financial sector varies. Bond issuance is accelerating significantly. Taking the example of the GCC, where capital markets are developing faster, bond issuance volumes have been increasing at a rate of 30 per cent for more than a decade, from a mere USD 9 billion total issuance in 2003 to USD 57 billion in 2012, and an accelerating trend leading to expected bond issuance levels of more than USD 8o billion in 2015 .

Another important phenomenon is the growing Sukuk (Sharia-compliant debt equivalent securities) market. Between 1996 and 2010, a total of 276 Sukuk bonds were issued in the GCC. For the year 2011 alone, 150 Sukuk bonds were issued. Domestic Sukuk amounts reached USD 120 billion in 2014, from a level of USD 5 billion equivalent in 2001, while the international Sukuk market saw issues increasing from USD 1.6 billion in 2003 to USD 28 billion in 2014, and increasing interest from non-Islamic or non-GCC or MENA participants-both sovereign and corporate issuers (IIFM, 2014; Markaz, 2010).

Debt issue trends observed in both conventional bond markets and more importantly in the Sukuk market point to strong and accelerating momentum, attracting international borrowers and investors. While the international $\mathrm{Su}$ kuk market remains small, its development - matching the pace of domestic and global issues from GCC-based borrowers-is an important indicator of the fact that these markets are gaining depth and credibility, an important factor in the further acceleration of growth.

Access to credit made available via capital markets remains limited; but the probability of a widening of the perimeter of new participants entering 
credit markets is increasing in line with the growth of the debt capital market. Furthermore, the existing actors involved in credit are changing the nature of their relationships, going from trust based on pre-existing relationships to an exchange of rights and obligations via instruments that are regulated and supervised within a set of rules and pricing mechanisms, and reflecting a trading activity that makes price, and its evolution, transparent to a wider set of potential participants.

The development of capital markets-based finance is in turn helping create additional rules and regulations and pushing the improvement of the regulatory and legal environment of the credit activities delivered through these channels. While the financial crisis in 2008 significantly slowed growth for two years, it also created in certain cases a need for restored credibility and the incentive to improve the regulatory environment. The quick recovery of issuance and volumes is testimony to the strength and potential of these markets.

The development of capital markets and credit has taken place within an environment of high oil prices in the last decade, generating tremendous cash reserves and making the need for credit less essential for economic activity. In the new context of significantly lower price levels, and considering the stress that this puts on the spending budgets of many MENA countries, credit is expected to play a more central role, accelerating the growth of its share in the financing of economic activities.

As credit growth accelerates, it will progressively shape and improve a governance framework that will provide a stronger foundation for increasing reliance on capital market debt. If the currently observed trends continue, we should see the ratio of credit to MENA countries' GDP rise, approaching levels observed in OECD economies. This will encourage a more open economic playing field, where people who do not necessarily have personal connections can trust each other, progressively influencing the way economies function and how they are fuelled by credit.

The rising market for debt eventually encourages the uptake of behaviour that resembles voting processes in the economic and financial sphere. This fosters changes in economic structure, which can also progressively promote democratic features in the political spheres of MENA.

Credit's role in OECD member democracies is at the core of the functioning of their economies. This does not mean that the credit system itself functions well at all times. The evolution of the credit inventory and its rate of growth, 
as well as instruments developed by the financial industry, can be the cause of major economic crises.

The crisis of 2008 showed how banks and financial markets, through their excessive use of leverage and their ability to 'exclude' competitors from the information and transparency necessary for the proper functioning of the system (particularly through the development of complex financial instruments known as derivatives), became one of the main reasons for the economic collapse.

One of the measures of a political system's strength can be the manner in which it reacts to crises and produces effective corrective actions. Credit's inventory size in OECD countries reached a level that was excessive compared to the underlying GDP. In this instance, credit became a risk to democratic processes and jeopardised the political sphere in which it operated.

An oversized credit inventory, operated by banks that are 'too big to fail', can be a risk for advanced OECD member democracies. Capital requirements were imposed on these banks, aiming to provide a more transparent 'price' for leverage rather than changing the mechanism at the core of the financial system.

MENA countries, in contrast, face the opposite risks, associated with credit being too small a component in the way economic activity is financed. The trends we have described with regards to the evolution of the financial sector in MENA point to a healthy and promising level of growth. These trends vary from country to country and are most evident in GCC member states. While such positive trends are solid, credit still plays too small a part in the financing of these economies to become a main agent of change towards greater reliance on democratic processes.

Regardless, the influence of credit is growing and the financial crisis of 2008 could end up having a positive impact. In 2009, several defaults in MENA were triggered as spillovers of the collapse of global capital markets. In particular, the default of Dubai's flagship corporations significantly impacted the emirate's access to credit and capital markets. The credibility of Dubai's implicit guarantees - on which previous loans and bonds, both international and domestic, were based-has been permanently damaged. This can have positive consequences if we consider that compliance with the more transparent and commonly used tools of guarantees and accounting will need to occur. This in turn improves the conditions for credit to grow, as it strengthens the quality of contracts struck between lenders and borrowers, potentially attracting new participants to the credit market.

The defaults of Kuwait's Investment Dar and Global Investment House, the liquidity difficulties of Gulf Bank in 2009, and-in Saudi Arabia and Bahrain - the Al-Gosaibi's financial crisis (triggered by the default of the International Banking Corporation and Awal Bank, controlled by Maan Al Sanea) 
did not endanger the overall solvency of the system given the relatively limited size of credit in the economies of those countries. However, the restructuring of these failed institutions' debt involved more than 80 banks internationally and domestically. This will tend to force the emergence of improved standards of accounting and increased transparency. The quality of guarantees that borrowers in the Kingdom of Saudi Arabia and in Kuwait will need to provide in order to access credit or issue Sukuks will need to improve. The acceleration of Sukuk issuance throughout the region and beyond reflects the improved quality of 'trust contracts' struck, and the increase in the number of participants accessing and providing credit.

At the end of 2014, the Egyptian government issued investment certificates soliciting the savings of national investors to fund infrastructure projects and the expansion of the Suez Canal. The transaction was a success: three weeks after the certificates were issued they sold out; the government netted USD 8.5 billion. The certificates represent an important commitment as they promise a return (12 per cent) and capital protection, providing credit guarantees based on the cash flow of the commercial activity of the Suez Canal as a security for capital and interest payments.

While an autocrat is again in power in Egypt, credit in this example introduces an element of commitment from the issuer or borrower towards the investors, similar to that of an electoral process, given the accountability that the certificates impose. It is difficult for the issuer to default on these commitments without damaging its credibility or facing consequences that would weaken its hold on power. The universe of investors that has subscribed to the certificates is obviously far from representative of the whole of Egyptian society, and only a few Egyptians that had the means to subscribe to the certificates are 'voters' in this exercise. Nevertheless, the process still imposes a significant degree of accountability.

\section{Conclusion}

Democratic transitions benefit from expanding credit within the economy. Autocratic governments that use the benefits of credit to finance growth are also faced with new governance obligations that increase the level of accountability in their regimes. For this reason, the trend towards a growth of the share of credit in the financing of MENA economies should be encouraged, especially by new democratic regimes.

One of the priorities of new democratic regimes should be the reform of the banking system and the promotion of capital markets-based finance in order 
to spread 'trust contracts' within their countries, helping to trigger higher levels of growth. The development of credit within a strong regulatory context, can only strengthen new democratic regimes.

\section{References}

CGAP (Consultative Group to Assist the Poor) (2010) Financial Access 2010: The State of Financial Inclusion Through the Crisis (Washington D.C.: CGAP/The World Bank Group) September, https://www.cgap.org/sites/default/files/CGAP-Financial -Access-2010.pdf (accessed on 27 March 2016).

ЕСB (European Central Bank) (2014) Banking Structures Report (Frankfurt am Main: ЕСВ), October, https://www.ecb.europa.eu/pub/pdf/other/bankingstructuresreport 201410.en.pdf (accessed on 27 March 2016).

Farazi, S., E. Feyen, R. Rocha and R. de Rezende (2011) Bank Ownership and Performance in Middle East and North Africa Regio, World Bank Policy Research Working Paper No. 5620, April (Washington D.C.: World Bank) Available at ss RN: http://ssrn.com/ abstract $=1803000$ (accessed on 27 March 2016).

IIFM (International Islamic Financial Market) (2014) Sukuk Report, A Comprehensive Study of the GlobalSukukMarket, 4th ed. (Manama, Bahrain: IIFM) November, http:// www.iifm.net/system/files/private/en/IIFM\%2oSukuk\%2oReport\%20\%284th $\% 20$ Edition $\% 29 \% 20 \mathrm{~A} \% 20$ Comprehensive\%20study\%20of\%2othe\%2oGlobal\%20 Sukuk\%20Market_o.pdf (accessed on 27 March 2016).

IMF (International Monetary Fund) (2004) Global Financial Stability Report: Market Developments and Issues (Washington D.C.: IMF), September, http://www.imf.org/ External/Pubs/FT/GFSR/2004/o1/index.htm (accessed on 27 March 2016).

Kern, S. (2012) GCc financial markets: Long-term prospects for finance in the Gulf region Deutsche Bank Research, (Frankfurt am Main : Deutsche Bank AG), November 14, https://www.dbresearch.com/PROD/DBR_INTERNET_EN-PROD/PROD ooooooooo0296909/GCC+financial+markets\% $\% 3$ A+Long-term+prospects+for+fina nce+in+the+Gulf+region.pdf (accessed on 27 March 2016).

Khamis, M. (2010) The Impact of the Global Financial Crisis on the Gcc Region: Lessons and Reform Priorities, Presentation at the Roundtable on Effective and Efficient Financial Regulation in the MENA Region, Doha December 6-7.

Leca J. (2014) Opening speech at the conference Whither the Arab World? Revisiting Democratic Transition Theory, (Paris: KFAS-SciencesPo) 5-7 November.

Markaz (2010) Gcc Bonds \& Sukuk Market Survey (Kuwait: Kuwait Financial Centre Markaz), October, http://www.markaz.com (accessed on 27 March 2016).

OECD (2014) Economic Survey Euro Area (Paris: OECD), April, DoI: 10.1787/eco _surveys-euz-2014-en. 